\title{
Perceptions Of Internet Technology In Small Businesses: An Empirical Comparison Of The U.S., Mexico And Croatia
}

F.J. Brewerton, (E-mail: brewerton@panam.edu), University of Texas-Pan American Martin Feinberg, (E-mail: feinbergm@panam.edu), University of Texas-Pan American

\begin{abstract}
There is a dearth of literature comparing the perceptions of small business executives from developed, developing and emerging countries regarding the utilization of Internet technology. This empirical study analyzes and compares survey responses from U.S., Mexican and Croatian small business executives regarding the utilization of 13 different aspects of information/Internet technology. The results indicate that U.S. small business executives have significantly higher perceptions than both Mexican and Croatian executives regarding the utilization of e-commerce, and that Croatian executives showed significantly higher perceptions than both U.S. and Mexican executives regarding the utilization of wireless phones.
\end{abstract}

\section{Introduction}

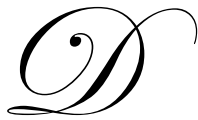

espite the seemingly ubiquitous presence of Internet technology manifestations, there is surprisingly little published research that focuses on the development and use of Internet technology in small businesses. Yet, the effective utilization of Internet technology is becoming increasingly critical for small businesses if they are to survive and prosper. Although basic cyberspace concepts and phenomena such as computers and computer networks, the use of network specialists, creation and use of web pages, periodic upgrades of connections, the presence and use of wireless phones, and utilization of the wireless Internet are fundamental to effectively accessing the Internet and its vast business potential, little is actually known concerning the presence and use of these concepts and phenomena in small businesses in developed countries, and even less is known concerning the presence and use of these components and concepts in small businesses in developing and emerging nations. This paper compares the perceptions of small business executives in the United States, Mexico and Croatia regarding the presence and use of selected basic elements and concepts of Internet technology in their respective businesses.

\section{Internet Technology in Developed Countries}

Approximately 88 percent of small and mid-sized businesses in the U.S. report that they have computers (Pechloff and Hexter, 2000). Fifty three percent of small and mid-sized businesses in the U.S. have a web page, up from 32 percent in 1998. Thirty nine percent have a network and fifteen percent can access their network from outside the office. Fourteen percent have a full-time network specialist. Internet usage among small businesses according to this survey has increased from 65 percent in 1998 to 85 percent in 2000, with e-mail and research being the most popular uses of the Internet among small and mid-sized businesses. Survey results also indicated that the modem was the most popular type of Internet connection (69\%), the wireless phone was commonly used (65\%) and that upgrade connections were not anticipated in the next twelve months (64\%). Wireless Internet was utilized by only $4 \%$ of the survey respondents (Pechloff and Hexter, 2000).

Singh, Jayashankar and Singh (2001) analyze and compare the development of Internet technology in Europe with that in the U.S. and conclude that even the most developed European economies lag well behind the U.S. with respect to Internet technologies development and growth. However, most of the European countries lead the U.S. in digital cell 
phone ownership and use, and are expected to be among the first countries to gain broad access to the net using digital phones in spite of a demonstrated reluctance to embrace e-commerce because of consumer distrust. Singh et al (2001) explains this reluctance through Europe's greater emphasis on maintaining privacy of personal information. In addition, Singh et al (2001) note that the development of Internet technology in Europe is inhibited by a shortage of web sites in different languages. As a consequence, Internet diffusion and access are still very low in such countries as Greece, Portugal and Spain. By contrast, the online population in Sweden and Norway approaches that of the U.S.

There are significant indications in the literature of the potential that e-commerce holds for small businesses. Onethird of small to mid-sized firms in the U.S. are currently using the Internet to find and attract new customers, but only 15 percent are actually conducting direct e-commerce at this time (Schultz, 1997), a percentage that is expected to increase significantly as these organizations look for new ways to sell directly to their customers. Internet opportunities are stimulating the development of Internet technology among small businesses as more of these businesses begin to view the Internet as their competitive advantage equalizer (Schultz, 1997).

Sterrett and Shah (1998) assert that small businesses need to explore the benefits and risks of cyberspace as an efficient method to both expand their markets and streamline supplier relationships. But they also caution that the Internet enables firms to efficiently seek business opportunities with low entry barriers thus making companies more visible and vulnerable to competition. Schultz's (1997) final conclusion is that the opportunities offered by the Internet comprise a special advantage for small businesses, enabling them to go global virtually overnight, and offering access to a customer base numbering in the millions and a global population of suppliers.

McDonagh and Prothero (2000) investigate the use of Internet technology in small and medium sized enterprises (SME's) in Ireland and conclude that Irish SME's compare favorably with larger organizations in regard to the use of email and the web. Almost $88 \%$ of Ireland's top 500 companies have an Internet connection with email, information gathering, and buying/selling goods being the most frequent usages of the Internet. McDonagh and Prothero (2000), also cite key factors that affect the adoption of information technology by SME's, including company size, management perceptions of information technology, employees' knowledge about relevant information systems, the availability of resources within the company, and the general day-to-day running mentality within the organizations.

\section{Internet Technology in Developing Countries}

Panayariya (2000), Anakwe, Arandarajan, and Igbaria (1999), and Luff (2000) all assert that the developing countries lag significantly behind the developed countries in regards to the use of Internet technology and the economic benefits associated with it. Panayariya (2000) analyzes developing countries' participation in e-commerce and, indirectly, their access to Internet services. Access to Internet services depends on the availability of communications networks, hardware, and software as well as access to existing communications networks. In developing countries hardware and software networks may not exist; similarly, communications networks may not exist or otherwise be accessible.

Panayariya (2000) concludes that developing countries may find that the expansion of e-commerce is a desirable instrument for achieving social and developmental goals, and should therefore make hardware and software widely available at reasonable prices, build basic infrastructure necessary for smooth functioning of the Internet, and negotiate access to developed country markets, all of which bode positively for the small business communities in these developing countries.

Anakwe, Arandarajan and Igbaria (1999) test hypotheses regarding the relationship between organizational support and computer usage, and computer experience and computer usage using data from the developing country Nigeria. Their study results indicate that organizational support enhances microcomputer use. Employees of all types and from all sizes of firms will spend more time on computers, use computers more often, and use more computer applications in an environment in which they feel supported. Anakwe et al (1999) also conclude that having computer experience increased employees' daily use of computers, their aggregate number of computer applications and the overall number of tasks employees performed using the computer. Finally, Anakwe et al (1999), extrapolate the Nigerian results 
as generalizable to other developing countries, but also suggest that cultural characteristics may play a role in the relationships confirmed by the study. In exploring the role of cultural factors in technology development, Neiderman (1997) compared differences in perceptions between U.S. facilitators and Mexican facilitators regarding computer software supported meetings. Neiderman's (1997) results suggest that reactions to a new technology may be quite similar across fairly different cultures but that culture probably accounts for some differences.

\section{Internet Technology in Emerging Countries}

Much less is known about the development of Internet technology in small businesses in emerging countries. Luff (2000) asserts that emerging markets are well aware of the potential benefits of Internet technology and utilization but lack the infrastructure and government fortitude for effective utilization.

Montealegre (1999) conducted an empirical study of Internet adoption in Chile, Costa Rica, Ecuador, and Peru to determine the role that institutions play in the adoption of information technology in less developed countries. Montealegre (1999) concluded that Internet adoption in less developed countries required major support from the government, the academic community, the private sector, telecommunications providers, and the international community.

Singh, et al (2001) asserts that the emerging countries are lacking in information technology capabilities and further stress the importance of technology penetration as a prerequisite for e-commerce.

\section{Purpose and Methodology}

The purpose of this study is to examine differences in small business executives' perceptions regarding Internet technology utilization in small businesses in the U.S., Mexico, and Croatia. The study will help provide a basis for determining the extent to which information technology is being used and its state and rate of development in small businesses in selected developed, developing and emerging countries. Participating respondents completed a questionnaire dealing with 13 aspects of Internet technology utilization. The first eleven of the questionnaire items focused on the perceived degree of utilization of specific elements of Internet technology. A twelfth question explored the degree to which the North American Free Trade Agreement (NAFTA) and/or the European Union (EU) trade agreements provided motivations to utilize computer technology. The thirteenth item in the questionnaire dealt with the type of connection speed utilized by the respondents.

The questionnaire was translated into the language of the three different countries to assure comprehension and administered to the respondents by the researchers. The questionnaire respondents included 103 executives from the U.S., 53 from Mexico, and 69 from Croatia. All of the respondents were employed by firms ranging in size from 3 to 250 employees. The first twelve items utilized a Likert-type response scale ranging from 1 (strongly disagree) to 7 (strongly agree). Participants responded objectively to item thirteen, which dealt with their type of connection speed. Each of the three study countries was chosen as representative of one of the broad categories of countries in the developed world (U.S.), the developing countries (Mexico), and the emerging market countries (Croatia). Croatia was selected for the survey because it was one of the first Central Eastern European countries to change to a global market driven economy in 1990. Lussier and Pfeifer (2000) note that the experiences of the emerging market of Croatia are similar to other Eastern European countries that are emerging market countries.

\section{Results and Discussion}

Table 1 provides the three-country summary of the descriptive statistics for the survey items. Table 2 presents the Analysis of Variance (ANOVA) results for the comparison test of the three countries. When there is statistical significance among the three countries, multiple comparison tests were conducted. Table 3 provides the results of the multiple comparisons test. 
Table 1. Descriptive Statistics

\begin{tabular}{|c|c|c|c|c|c|c|}
\hline & \multicolumn{2}{|l|}{ US } & \multicolumn{2}{|l|}{ Mexico } & \multicolumn{2}{|c|}{ Croatia } \\
\hline & Mean* & SD & Mean* & SD & Mean* & SD \\
\hline $\begin{array}{l}\text { Use of e-commerce } \\
\text { (ECOM) }\end{array}$ & 3.08 & 1.94 & 2.64 & 1.54 & 2.02 & 1.16 \\
\hline $\begin{array}{l}\text { Use of computer networks } \\
\text { (CNET) }\end{array}$ & 5.30 & 2.16 & 4.26 & 2.57 & 3.13 & 1.57 \\
\hline $\begin{array}{l}\text { Share information via Internet } \\
\text { (SHARE) }\end{array}$ & 3.85 & 2.32 & 3.52 & 2.10 & 2.23 & 1.51 \\
\hline $\begin{array}{l}\text { Access to information out of office } \\
\text { (ACCESS) }\end{array}$ & 3.07 & 2.31 & 2.54 & 1.82 & 1.72 & 1.13 \\
\hline $\begin{array}{l}\text { Use of computer specialist } \\
\text { (CSPEC) }\end{array}$ & 4.37 & 2.06 & 3.28 & 1.79 & 2.04 & 1.23 \\
\hline $\begin{array}{l}\text { Utilize Internet } \\
\text { (USEINTR) }\end{array}$ & 4.17 & 1.13 & 4.03 & 1.62 & 4.21 & 1.39 \\
\hline $\begin{array}{l}\text { Utilize Web-page } \\
\text { (WEBPAGE) }\end{array}$ & 3.96 & 1.25 & 4.01 & 1.43 & 4.11 & 1.74 \\
\hline $\begin{array}{l}\text { Plan to upgrade within } 1 \text { year } \\
\text { (UPGRADE) }\end{array}$ & 3.85 & 2.27 & 4.39 & 1.69 & 3.56 & 1.28 \\
\hline $\begin{array}{l}\text { Use of wireless phone } \\
\text { (WPHONE) }\end{array}$ & 4.87 & 2.27 & 4.33 & 2.03 & 6.88 & 0.73 \\
\hline $\begin{array}{l}\text { Use of wireless beeper } \\
\text { (WBEEPER) }\end{array}$ & 2.96 & 2.29 & 1.98 & 1.52 & 4.47 & 2.91 \\
\hline $\begin{array}{l}\text { Use of wireless Internet } \\
\text { (WINTERNET) }\end{array}$ & 2.36 & 2.07 & 1.07 & 0.33 & 1.08 & 0.61 \\
\hline $\begin{array}{l}\text { NAFTA/EU provides motivation for } \\
\text { tech utilization } \\
\text { (NAFTA/EU) }\end{array}$ & 2.75 & 2.14 & 2.96 & 1.60 & 2.82 & 1.75 \\
\hline Total Number of Firms & 103 & & 53 & & 69 & \\
\hline
\end{tabular}

* mean perception based on 1-7 Likert-scale, $1=$ strongly disagree, $7=$ strongly agree

The ANOVA results (Table 2) and the multiple comparisons (Table 3) suggest that U.S. small business executives have significantly higher perceptions than both Mexican and Croatian executives regarding the utilization of e-commerce (ECOM), utilization of computer networks (CNET), utilization of computer specialists (CSPEC), and utilization of wireless Internet (WINTERNET).

Mexican executives showed significantly higher perceptions than Croatian executives in regards to the utilization of computer networks (CNET), sharing of information via the Internet (SHARE), access to information out of the office (ACCESS), and the use of computer specialists (CSPEC).

Croatian executives showed significantly higher perceptions than both U.S. and Mexican executives regarding the utilization of wireless phones (WPHONE) and the utilization of wireless beepers (WBEEPER).

More generally, the survey results suggest there is a rank order relationship between perceptions of U.S. small business executives, Mexican small business executives, and Croatian small business executives regarding the utilization of information technology, with U.S. executive perceptions being the highest and Croatian executive perceptions being the lowest. Of the eight variables manifesting significant differences between countries, U.S. perceptions were significantly higher than Mexican perceptions on five of the eight variables, and significantly higher than Croatian perceptions on six of the eight variables. Mexican perceptions were significantly higher than Croatian perceptions on four of the eight variables manifesting significant differences between countries. Only in regard to the utilization of wireless phones (WPHONE) and wireless beepers (WBEEPER) did Croatian executives have higher perceptions than U.S. and Mexican executives. 
Table 2 ANOVA Results

\begin{tabular}{|c|c|c|c|c|c|c|}
\hline & & Sum of Squares & df & Mean Square & $\mathbf{F}$ & Sig. \\
\hline ECOM & $\begin{array}{l}\text { Between Groups } \\
\text { Within Groups } \\
\text { Total }\end{array}$ & $\begin{array}{l}124.4 \\
658.7 \\
783.1\end{array}$ & $\begin{array}{l}2 \\
224 \\
226\end{array}$ & $\begin{array}{l}62.2 \\
2.9\end{array}$ & 21.1 & $0.000^{*}$ \\
\hline CNET & $\begin{array}{l}\text { Between Groups } \\
\text { Within Groups } \\
\text { Total }\end{array}$ & $\begin{array}{l}213.5 \\
957.1 \\
1170.6\end{array}$ & $\begin{array}{l}2 \\
224 \\
226\end{array}$ & $\begin{array}{l}106.7 \\
4.24\end{array}$ & 24.9 & $0.000 *$ \\
\hline SHARE & $\begin{array}{l}\text { Between Groups } \\
\text { Within Groups } \\
\text { Total }\end{array}$ & $\begin{array}{l}106.5 \\
905.6 \\
1012.1\end{array}$ & $\begin{array}{l}2 \\
224 \\
226\end{array}$ & $\begin{array}{l}53.2 \\
4.1\end{array}$ & 12.7 & $0.000^{*}$ \\
\hline ACCESS & $\begin{array}{l}\text { Between Groups } \\
\text { Within Groups } \\
\text { Total }\end{array}$ & $\begin{array}{l}90.1 \\
760.6 \\
850.8\end{array}$ & $\begin{array}{l}2 \\
217 \\
219\end{array}$ & $\begin{array}{l}45.1 \\
3.5\end{array}$ & 12.8 & $0.000^{*}$ \\
\hline CSPEC & $\begin{array}{l}\text { Between Groups } \\
\text { Within Groups } \\
\text { Total }\end{array}$ & $\begin{array}{l}235.7 \\
665.9 \\
901.6\end{array}$ & $\begin{array}{l}2 \\
217 \\
219\end{array}$ & $\begin{array}{l}117.8 \\
3.1\end{array}$ & 38.4 & $0.000^{*}$ \\
\hline USEINTR & $\begin{array}{l}\text { Between Groups } \\
\text { Within Groups } \\
\text { Total }\end{array}$ & $\begin{array}{l}22.0 \\
2545.7 \\
2567.7\end{array}$ & $\begin{array}{l}2 \\
229 \\
231\end{array}$ & $\begin{array}{l}11.0 \\
11.1\end{array}$ & 0.991 & 0.373 \\
\hline WEBPAGE & $\begin{array}{l}\text { Between Groups } \\
\text { Within Groups } \\
\text { Total }\end{array}$ & $\begin{array}{l}1.2 \\
70.0 \\
71.3\end{array}$ & $\begin{array}{l}2 \\
229 \\
231\end{array}$ & $\begin{array}{l}0.642 \\
0.306\end{array}$ & 2.096 & 0.125 \\
\hline UPGRADE & $\begin{array}{l}\text { Between Groups } \\
\text { Within Groups } \\
\text { Total }\end{array}$ & $\begin{array}{l}20.4 \\
762.9 \\
783.3\end{array}$ & $\begin{array}{l}2 \\
217 \\
219\end{array}$ & $\begin{array}{l}10.2 \\
3.5\end{array}$ & 2.9 & 0.057 \\
\hline WPHONE & $\begin{array}{l}\text { Between Groups } \\
\text { Within Groups } \\
\text { Total }\end{array}$ & $\begin{array}{l}229.9 \\
763.5 \\
993.4\end{array}$ & $\begin{array}{l}2 \\
217 \\
219\end{array}$ & $\begin{array}{l}114.9 \\
3.5\end{array}$ & 32.6 & $0.000^{*}$ \\
\hline WBEEPER & $\begin{array}{l}\text { Between Groups } \\
\text { Within Groups } \\
\text { Total }\end{array}$ & $\begin{array}{l}191.7 \\
1213.5 \\
1405.2\end{array}$ & $\begin{array}{l}2 \\
217 \\
219\end{array}$ & $\begin{array}{l}95.8 \\
5.6\end{array}$ & 17.1 & $0.000^{*}$ \\
\hline WINTERNET & $\begin{array}{l}\text { Between Groups } \\
\text { Within Groups } \\
\text { Total }\end{array}$ & $\begin{array}{l}95.9 \\
440.1 \\
536.0\end{array}$ & $\begin{array}{l}2 \\
217 \\
219\end{array}$ & $\begin{array}{l}47.9 \\
2.0\end{array}$ & 23.6 & $0.000^{*}$ \\
\hline NAFTA/EU & $\begin{array}{l}\text { Between Groups } \\
\text { Within Groups } \\
\text { Total }\end{array}$ & $\begin{array}{l}1.5 \\
781.8 \\
783.3\end{array}$ & $\begin{array}{l}2 \\
217 \\
219\end{array}$ & $\begin{array}{l}0.7 \\
3.6\end{array}$ & 0.2 & 0.806 \\
\hline
\end{tabular}

* Significant at .05 or less

There were no significant differences among perceptions of the survey respondents from all three countries regarding the degree of utilization of the Internet (USEINTR), the utilization of web pages (WEBPAGE), the plans to upgrade systems (UPGRADE), and the motivation provided by trade agreements to pursue the development of information technology (NAFTA/EU). The mean response values of all three countries for these variables (Table 1) indicate utilization levels for web pages and the Internet are neither extremely high nor extremely low and are concentrated near the mid-scale value of 4.0. Similarly, the mean responses from all three groups regarding plans to upgrade suggest that such plans are formulated or are being formulated, but the absence of extreme values in the responses suggests that these plans are neither urgent nor are they being overlooked. 
Table 3 Multiple Comparisons

\begin{tabular}{|l|ll|c|c|c|c|}
\hline Dep. Variable & (I) COUNTRY & (J) COUNTRY & Mean Diff. (I-J) & Std. Error & Sig. \\
\hline ECOM & U.S. & vs & Mexico & 1.05 & 0.29 & $0.002^{*}$ \\
& U.S. & vs & Croatia & 1.68 & 0.26 & $0.000^{*}$ \\
& Mexico & vs & Croatia & 0.63 & 0.31 & 0.130 \\
& U.S. & vs & Mexico & 1.07 & 0.35 & $0.010^{*}$ \\
& U.S. & vs & Croatia & 2.24 & 0.32 & $0.000^{*}$ \\
SHARE & Mexico & vs & Croatia & 1.17 & 0.37 & $0.008^{*}$ \\
& U.S. & vs & Mexico & 0.28 & 0.35 & 0.721 \\
& U.S. & vs & Croatia & 1.60 & 0.32 & $0.000^{*}$ \\
ACCESS & Mexico & vs & Croatia & 1.32 & 0.37 & $0.008^{*}$ \\
& U.S. & vs & Mexico & 0.56 & 0.32 & 0.212 \\
CSPEC & U.S. & vs & Croatia & 1.60 & 0.32 & $0.000^{*}$ \\
& Mexico & vs & Croatia & 1.32 & 0.38 & $0.026^{*}$ \\
& U.S. & vs & Mexico & 1.08 & 0.30 & $0.002^{*}$ \\
WPHONE & U.S. & vs & Croatia & 2.43 & 0.28 & $0.000^{*}$ \\
& Mexico & vs & Croatia & 1.34 & 0.32 & $0.000^{*}$ \\
& U.S. & vs & Mexico & 0.58 & 0.32 & 0.191 \\
WBEEPER & U.S. & vs & Croatia & -1.97 & 0.30 & $0.000^{*}$ \\
& Mexico & vs & Croatia & -2.55 & 0.35 & $0.000^{*}$ \\
& U.S. & vs & Mexico & 1.02 & 0.40 & $0.047^{*}$ \\
& U.S. & vs & Croatia & -1.48 & 0.37 & $0.001^{*}$ \\
WINTERNET & Mexico & vs & Croatia & -2.50 & 0.44 & $0.000^{*}$ \\
& U.S. & vs & Mexico & 1.29 & 0.24 & $0.000^{*}$ \\
& U.S. & vs & Croatia & 1.35 & 0.23 & $0.000^{*}$ \\
& Mexico & vs & Croatia & 0.00 & 0.26 & 0.974 \\
\hline
\end{tabular}

* Significant at .05 or less.

Mildly surprising are the responses to the question regarding the motivation provided by trade agreements such as NAFTA and EU to utilize information technology. All three countries' responses were on the lower end of the scale (U.S. $=2.25$; Mexico = 2.96; Croatia $=1.75)$ and were not significantly different from each other. The relatively low values of these responses suggest that trade agreements such as NAFTA and EU are not a major motivating force for small business executives to utilize information technology in any of the three countries involved in this study.

Additional depth and insight regarding the extent to which survey respondents utilize information technology was obtained by performing a two-group discriminant analysis of the survey responses. A categorical dependent variable was constructed using the polar extremes approach applied to the survey responses to the question relating to the utilization of e-commerce (ECOM) as described in Hair et al (1998). The 1 to 7-response scale was portioned into three categories, with scale responses 1 and 2 defining the "light users of e-commerce" category and scale responses 6 and 7 defining the "heavy users of e-commerce" category. The middle scale responses $(3,4,5)$ were excluded in the analysis.

A stepwise approach (Hair, et al, 1998) was used to estimate the discriminant function considering the responses to 12 survey questions (exclusive of the connection speed question) as independent variables. An additional independent variable - number of employees in the firm - was also considered in the estimation of the discriminant function. Utilization of web-pages (WEBPAGE) was the first variable to enter the discriminant function (as the single best discriminating variable), followed by the SHARE variable. All other independent variables considered were judged as not contributing significantly to further discrimination. Table 4 presents the ensuing structured matrix and load factors. Table 5 presents the results of the discriminant analysis. Light users were correctly classified in 99 of 115 cases (86\%), while heavy users were correctly classified in 35 of 37 cases $(94.6 \%)$. Overall, the discriminant function correctly classified 134 of 152 cases for a hit ratio of $88.2 \%$. 
Table 4 Structure Matrix and Load Factors

\begin{tabular}{|l|c|c|}
\hline Discriminant Function & Variable & Load Factor (Correlations) \\
\hline In Analysis & WEBPAGE SHARE & .850 \\
& & .795 \\
\hline \multirow{5}{*}{ Not In } & CSPEC & .643 \\
Analysis & CNET & .597 \\
& ACCESS & .592 \\
& USEINTR & .565 \\
& WINTERNET & .449 \\
& NAFTA/EU & .347 \\
& UPGRADE & .307 \\
& NUMEMPLO & .253 \\
& WPHONE & -.158 \\
& WBEEPER & -.065 \\
& CONNECT & -.027 \\
\hline
\end{tabular}

Table 5 Comparisons Results

\begin{tabular}{|l|c|c|c|}
\hline \multirow{2}{*}{ Usage of E-Commerce } & \multicolumn{2}{|c|}{ Predicted Group } & \multirow{2}{*}{ Total } \\
\cline { 2 - 3 } & Light Users & Heavy Users & 115 \\
Category 1: Light Users & 99 & 16 & 37 \\
Category 2: Heavy Users & 2 & 35 & 90 \\
Ungrouped Cases & 40 & 50 & 50 \\
\hline
\end{tabular}

Finally, Table 6 presents the results of the objective responses to question 13 dealing with connection speed. Respondents were asked to indicate the type of connection speed they utilized by circling one of the five possible responses. The pattern of responses for U.S. and Mexican executives was similar with the greatest percentages of both of these countries' respondents indicating a connection speed of 56K (U.S. $=59.8 \%$ and Mexico $=48.1 \%$ ). Progressively smaller percentage responses for each higher connection speed category were generally evident for both countries. Very small percentages of the responses (U.S. $=3.3 \%$, Mexico $=7.7 \%$ ) indicated that they had no connection of any type or speed. Somewhat surprisingly, only $21.2 \%$ of the Croatian executives reported a connection speed of $56 \mathrm{~K}$, a percentage that is barely one-third of the percentage reported by U.S. executives and less than half of the percentage reported by Mexican executives. But the percentage of Croatia's executives reporting connection speeds in the 144-384K range was almost three times that of the U.S. (68.2\% versus $23.9 \%)$ and almost two and one-half times that of the Mexican executives (68.2\% versus 28.8\%). However, Croatia reported no connection speeds higher than the 144-384K range, and its percentage of executives with no connection of any type or speed was over three times that of the U.S. (10.6\% versus $3.3 \%$ ) and about 1.4 times that of Mexico (10.6\% versus $7.7 \%$ ).

Table 6 Connection Speed Statistics by Country

\begin{tabular}{|l|c|c|c|c|c|c|c|}
\hline \multicolumn{2}{|c|}{ Connection speed by country } & & \multicolumn{1}{c|}{ Total } \\
\hline & CONNECTION & $56 \mathrm{~K}$ & $144-384 \mathrm{~K}$ & $416-784 \mathrm{~K}$ & $1 \mathrm{M}$ & none & \\
\hline US & Number & 55 & 22 & 7 & 5 & 3 & 92 \\
Mexico & \% within U.S. & $59.8 \%$ & $23.9 \%$ & $7.6 \%$ & $5.4 \%$ & $3.3 \%$ & $100.0 \%$ \\
& Number & 25 & 15 & 3 & 5 & 4 & 52 \\
Croatia & \% within Mexico & $48.1 \%$ & $28.8 \%$ & $5.8 \%$ & $9.6 \%$ & $7.7 \%$ & $100.0 \%$ \\
& Number & 14 & 45 & -- & -- & 7 & 66 \\
& \% within Croatia & $21.2 \%$ & $68.2 \%$ & -- & - & $10.6 \%$ & $100.0 \%$ \\
& Number & 94 & 82 & 10 & 10 & 14 & 210 \\
& \% within Total & $44.8 \%$ & $39.0 \%$ & $4.8 \%$ & $4.8 \%$ & $6.7 \%$ & $100.0 \%$ \\
\hline
\end{tabular}


One possible explanation for these major differences in connection speed may be the current state of information technology infrastructure development in the subject countries. In a country ravaged by warring factions and the accompanying destruction of older infrastructure it would be reasonable to expect that newer technology would be utilized in the reconstruction of infrastructure for the future in an emerging market country. Newer technology would logically be related to higher connection speeds and significantly higher use of both wireless phones and wireless beepers, both of which are indicated by the survey results. Replications of this study over time may provide a basis for confirming these explanations.

\section{Conclusions}

This study provides valuable new information of both a general and specific nature regarding the utilization of information technology in small businesses in the three countries surveyed. In general, the results of this study focusing on small business are consistent with the results reported in prior studies focusing on the general state of information technology utilization in developed countries. This study helps confirm that the broad and general utilization of information technology reported by earlier studies extends through the small business community in developed countries.

The results of this study may also be treated as a benchmark for specific aspects of small business information technology utilization in Mexico and Croatia and provides a general reference point for the conduct of future studies examining other aspects of information technology utilization in small businesses in the subject countries. This study may also serve as a basis for broader groupings of developing and emerging countries to the extent that the results are generalizeable.

An additional conclusion is that there is a rank order relationship between the perceptions of U.S. executives (highest), Mexican executives (next highest), and Croatian executives (lowest) regarding the use of information technology in the small business communities in these countries. This relationship is consistent with findings of other studies in the literature that report the highest information technology usage in the developed countries, lower usage in the developing countries, and lowest usage in emerging countries.

Although there were significant differences between the different countries' responses to specific survey questions, the overall survey results suggest that the rate of information technology development in small businesses is rapid in the three countries surveyed. To the extent that the overall survey results are generalizeable, it may be concluded that information technology development in small businesses is occurring at a swift pace globally and is impacting the developing and emerging countries dramatically. Additionally, the survey results and the discriminant analysis provide strong insights for categorizing small business executives into "heavy users" and "light users" of e-commerce.

Croatia's higher connection speeds were unexpected but may not be generalizeable as typical of other emerging countries. Croatia's unique recent experiences with political and military strife, its accompanying destruction of infrastructure, and its rebuilding of information infrastructure may well explain its superior connection speeds. Additional research may provide data-based explanations for Croatia's higher connection speeds.

The survey results also lead to conclusions that were unexpected in regard to (1) the motivation provided by trade agreements to utilize information technology, and (2) connection speeds in developing and emerging countries. Trade agreements between blocs of countries clearly do not appear to be a major source of motivation for small businesses to utilize information technology. Fundamental market and competitive forces may be the more important motivation driving information technology development in the small business arena. Future research studies that specifically explore this issue may provide more succinct explanations regarding the motivation for information technology development. 


\section{References}

1. Anakwe, U., Anandarajan, M., and Igbaria, M., 1999. "Information Technology Usage Dynamics in Nigeria: An Empirical Study," Journal of Global Information Management, 7, 2, April-June, 13-21.

2. Hair, J., Anderson, R., Tatum, R., and Black, W., 1998. Multivariate Data Analysis, 5th Edition, Prentice-Hall, Upper Saddle River, N.J.

3. Luff, D., 2000. "E-merging Markets," Global Finance, 14, 2, 54-56.

4. Lussier, R. and Pfeifer, S., 2000. "A comparison of business versus failure variables between U.S. and Central Eastern Europe Croatian entrepreneurs," Entrepreneurship Theory \& Practice, 24, 4, summer, 59-67.

5. McDonagh, P., and Prothero, A., 2000. "Eurolicking and the Irish SME: Prepared for e-commerce and the single commerce?” Irish Marketing Review-Dublin, 13, 1, 21-33.

6. Montealegre, R., 1999. "A Temporal Model of Institutional Interventions for Information Technology Adoption in Less-Developed Countries,” Journal of Management Information Systems, 16, 1, 207-232.

7. Niederman, F., 1997. "Facilitating Computer-Supported Meetings: An Exploratory Comparison of U.S. and Mexican Facilitators," Journal of Global Information Management, 5, 1, winter, 17-26.

8. Panagariya, A., 2000. "E-Commerce, WTO and developing countries," World Economy, 23, 8, August, 959978.

9. $\quad$ Pechloff, N. and Hexter, J., (eds.), 2000. "NSBU Survey of small and mid-sized businesses: Trends for 2000: conducted by Arthur Andersen and National Small Business United.

10. Schultz, J., 1997. "Revolutionary selling," Management Review, 86, 10, November, 22-24.

11. Singh, T., Jayashankar, J., and Singh, J., 2001. "E-Commerce in the U.S. and Europe-Is Europe Ready to Compete," Business Horizons, 44, 2, 6-16.

12. Sterrett, C., and Shah, A., 1998. "Going global on the information super highway," SAM Advanced Management Journal, 63, 1, 43-48. 
Notes 